Communications in Physics, Vol. 28, No. 3 (2018), pp. 217-224

DOI: $10.15625 / 0868-3166 / 28 / 3 / 10758$

\title{
STUDY TO FABRICATE THE LARGE SCALE BUCKYPAPER BASED ON CARBON NANOTUBES
}

\author{
DOANH TU TIEU ${ }^{1}$, MY KHANH NGUYEN ${ }^{3}$, THAM THI HONG NGUYEN ${ }^{1}$, \\ THANH VO KE NGO ${ }^{1,2}$ AND QUYET HUU DO ${ }^{1, \dagger}$
}

${ }^{1}$ Sai Gon Hi Tech Park Labs, Sai Gon Hi Tech Park, District 9, Ho Chi Minh City, Vietnam

${ }^{2}$ Institute for Computational Science and Technology, SBI building, Quang Trung Software City, Tan Chanh Hiep ward, district 12, Ho Chi Minh city, Vietnam

${ }^{3}$ University of Natural Science, 227 Nguyen Van Cu, District 5, Ho Chi Minh City, Vietnam

${ }^{\dagger} E$-mail: quyet.dohuu@shtplabs.org

Received 25 September 2017

Accepted for publication 20 July 2018

Published 31 August 2018

\begin{abstract}
Carbon nanotubes (CNTs) have attracted great attention because of their unique structural, electrical, mechanical and thermal properties. Then CNTs have potential application as thermal pads, electrodes for batteries and supercapacitors, especially binder-free electrodes. The major challenge is to fabricate the large scale electrode with the uniform thickness, electrical property. The large scale CNTs buckypaper can be fabricated via vacuum filtration technique. The characteristics of CNT dispersion and buckypaper depend on variety of factor such as sonication power, sonication time, dispersant.... In this study, we investigate the multiwall carbon nanotubes (MW CNTs) in IsoPropanol (IPA) solvent with different sonication conditions, membrane filter size for paper with areal density of $3 \mathrm{mg} / \mathrm{cm}^{2}$ with different sizes such as $4,10,20 \mathrm{~cm}$ in diameter and large scale of $30 \times 30 \mathrm{~cm}^{2}$. It is observed that the dispersion of CNTs are good and the thickness, conductivity are uniform over whole sample for above sizes. We also can get the highest conductivity of buckypaper was $3.9 \times 10^{3} \mathrm{~S} / \mathrm{m}$ in 30 minutes. It is found that the higher sonication power and higher sonication time are better for buckypaper.
\end{abstract}

Keywords: carbon nanotubes, buckypaper, buckypaper electrode, membrane filtration, porous structure.

Classification numbers: 61.48.De.

(C)2018 Vietnam Academy of Science and Technology 


\section{INTRODUCTION}

Carbon nanotubes have attracted great attention because of their unique structural, electrical, mechanical and thermal properties [1,2]. Buckypapers are thin films formed with dispersed network of CNTs. Now, techniques for fabricating buckypaper can be classified into dry and wet approaches. The dry approaches include the direct in situ chemical vapor deposition (CVD) growing, domino pushing [3] and shear pressing [4]. These approaches give structural perfection but less degree of CNTs agglomeration. On the other hand, the wet approaches such as membrane filtration [4-7], drop casting [8,9], spin-coating [10] and electrophoresis deposition [11,12] are more attractive due to cost effectively scaled up. In this wet approach, membrane filtration technique is often used as 1) it is the easy and simple process, 2) it can control thickness of buckypaper precisely 3) it can be mixed with carbon family such as graphene, graphite, carbon nano-fibers and 4) it can be scaled up. This technique involves dispersion solution and usually added the surfactant as Triton X-100 or Sodium Lauryl Sufate in order to improve the dispersion ability. However, when the buckypaper was successfully fabricated, we need to remove the residual surfactant from it. This way can break or even destroy the buckypaper. Besides, the surfactant linked into CNTs matrix will reduce buckypaper properties such as decrease the electrical, thermal conductivity.

In this work, we use the membrane filtration method to fabricate the buckypaper without adding the surfactant into solution in order to avoid the above problems [13]. We will study the the affecting factors such as sonication (power and time), membrane filter size to get the highest quality of the buckypaper.

\section{EXPERIMENT}

\section{II.1. Buckypaper fabrication}

A buckypaper is a network of CNTs in the form of thin film, fabricated by dispersion and filtration. The CNTs were purchased from Cheaptube, Inc (USA) and poured into the IPA solution. Then the mixture was dispensed by high power sonicator UIP 1000HD (Germany) with different power and time. We also fabricate the buckypaper with different size 4, 10, $20 \mathrm{~cm}$ diameter and $30 \times 30 \mathrm{~cm}^{2}$ square with area density $3 \mathrm{mg} / \mathrm{cm}^{2}$. After the solution filtration, the buckypaper was dried at room temperature in few hours to evaporate the IPA and brought to characterization.

\section{II.2. Characterization}

Morphologies of the raw CNTs and Buckypaper were investigated using the Field Emisson Scanning Electron Microscope (FE SEM S4800, Hitachi) with an accelerating voltage of 10kV. With FE SEM images, we can see how the agglomerative level of CNTs net-work. The thickness of buckypaper was measured by Micrometer Mitutoyo. Electrical conductivity of the buckypaper was obtained by Four - point probe method (Jandel Model MWP-8). The Quantachrome Instruments Nova 1000 e (USA) is used to analyze the surface area of the sample.

\section{RESULTS AND DISCUSSION}

The raw CNTs were characterized by FE SEM to characterize before they were used to fabricate the Buckypaper. We saw that the CNTs were uniform in the length about 20 um, diameter about 10-20 nm and high purity in Fig. 1. The pictures of buckypaper samples with small diameter of $4 \mathrm{~cm}$ and larger size of $30 \times 30 \mathrm{~cm}^{2}$ were shown in Fig. 2 . 

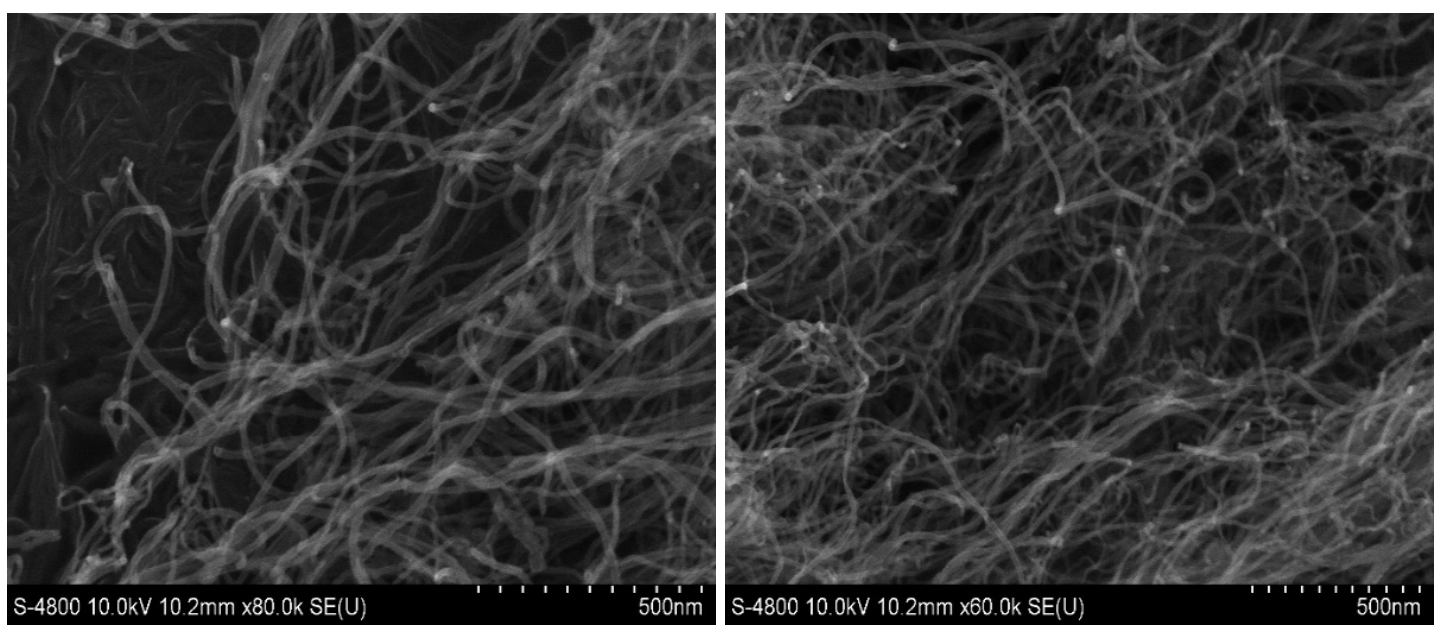

Fig. 1. The FE SEM images of the raw CNTs purchasing from manufacturer.

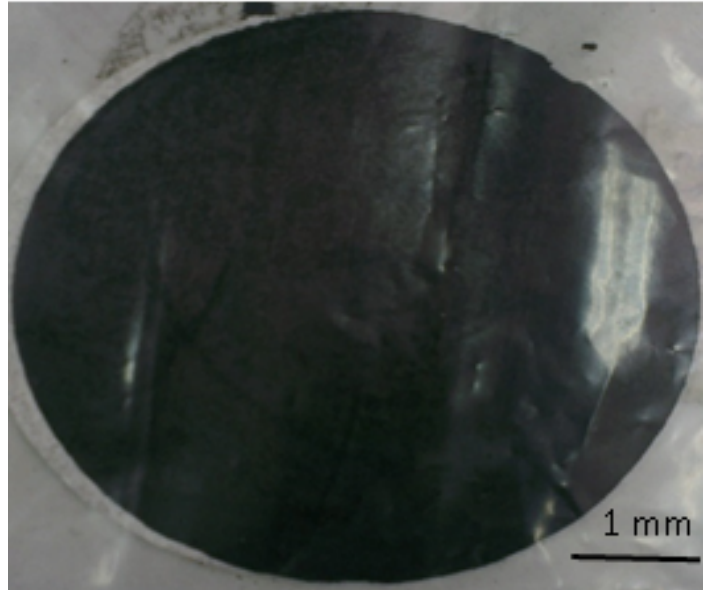

(a)

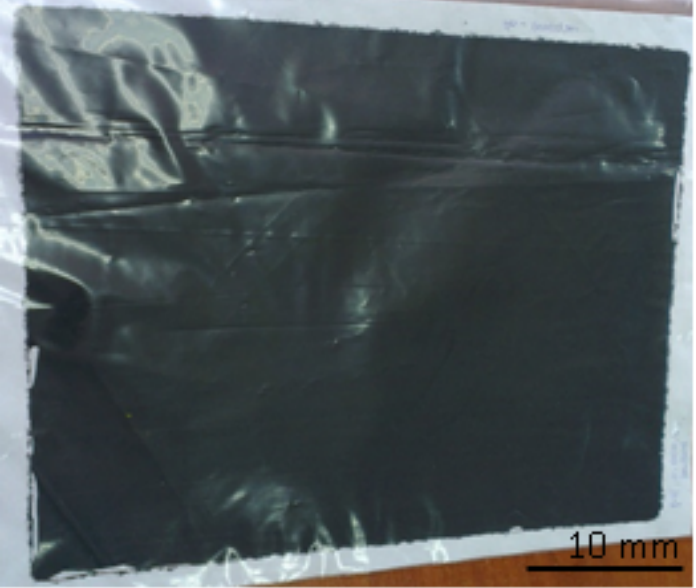

(b)

Fig. 2. The pictures of Buckypaper samples with different sizes a) $4 \mathrm{~cm}$ diameter; b) $30 \times 30 \mathrm{~cm}^{2}$ square.

\section{III.1. Micro-mophologies of the Buckypaper}

In the sonication process, the CNTs were not be shortened or destroyed although the time sonication increased from 10, 20 to 30 minutes or the power sonication was 500, 700, 900 and highest power $1000 \mathrm{~W}$, respectively. This showed that these sonication time and power do not affect to the CNTs quality and Buckypaper as well in Figs. 3-4. It means with these sonication time less than or equal 30 minutes and power $1000 \mathrm{~W}$ do not affect to the CNTs quality and Buckypaper. If the sonication time is more than 30 minutes, the CNTs will be shortend in Figs. 5-6, which will degrade the both CNTs quality and Buckypaper. 

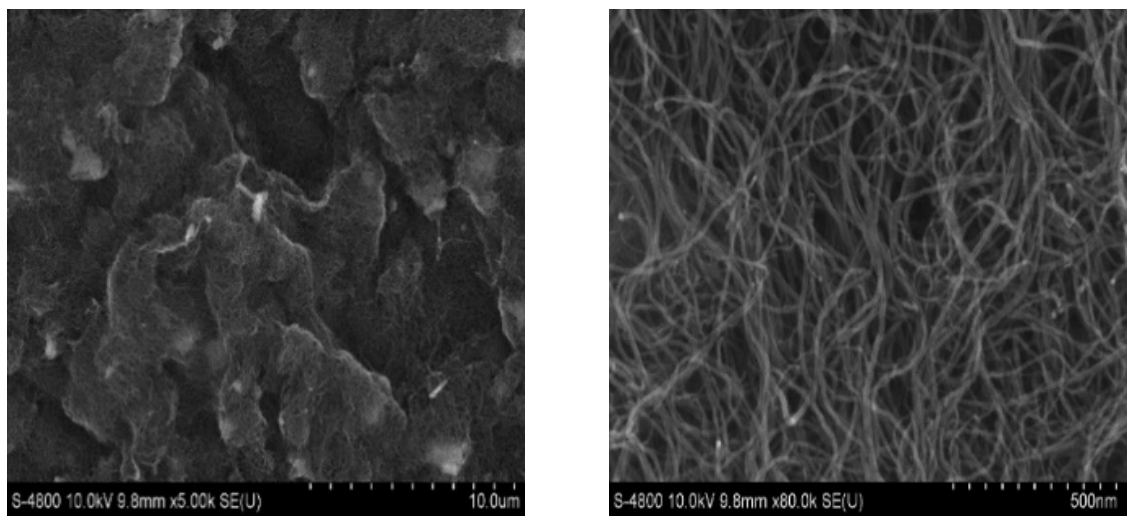

(a)
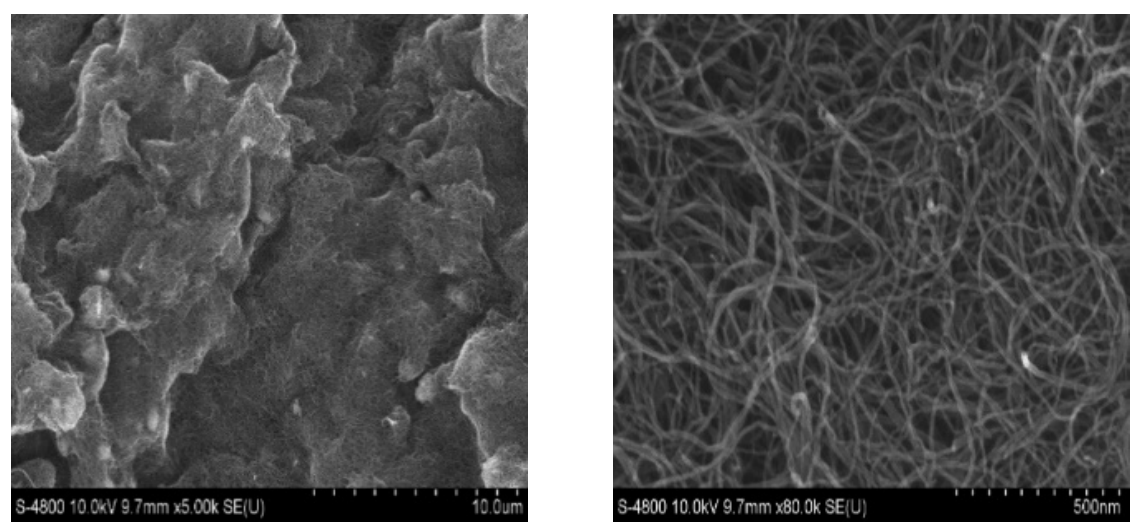

(b)
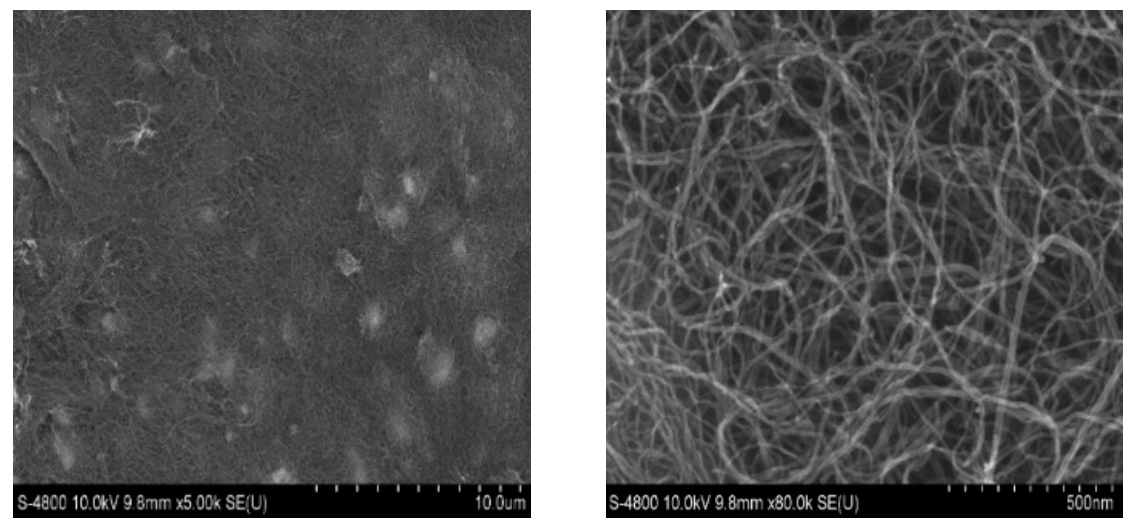

(c)

Fig. 3. The FE SEM images of Buckypaper samples fabricated by vacuum filtration technique with varied sonication time a) 10 minutes; b) 20 minutes; and c) 30 minutes. 


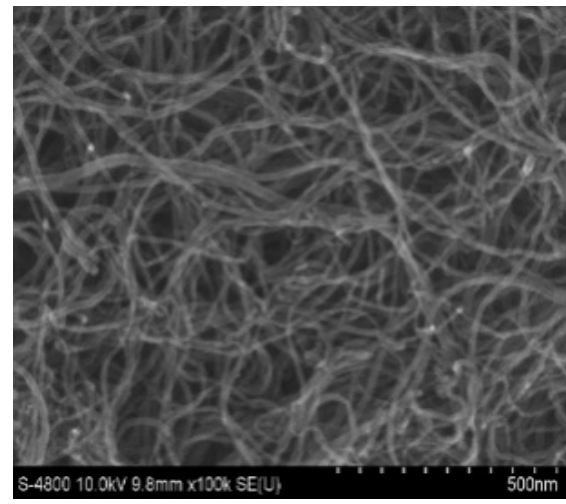

(a)

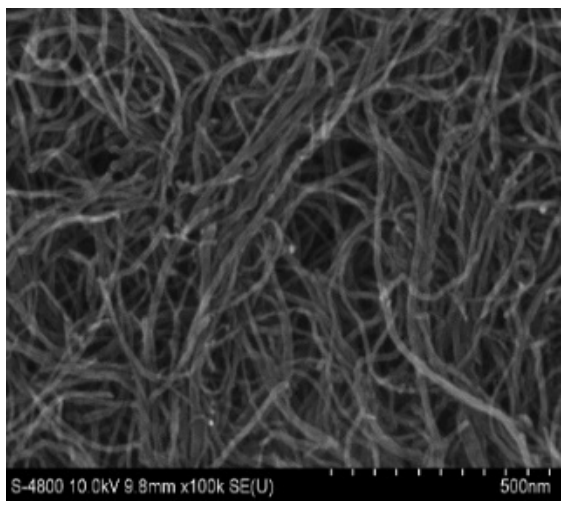

(c)

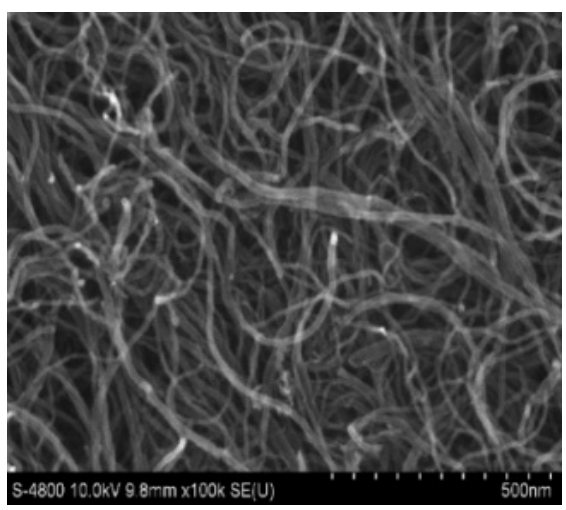

(b)

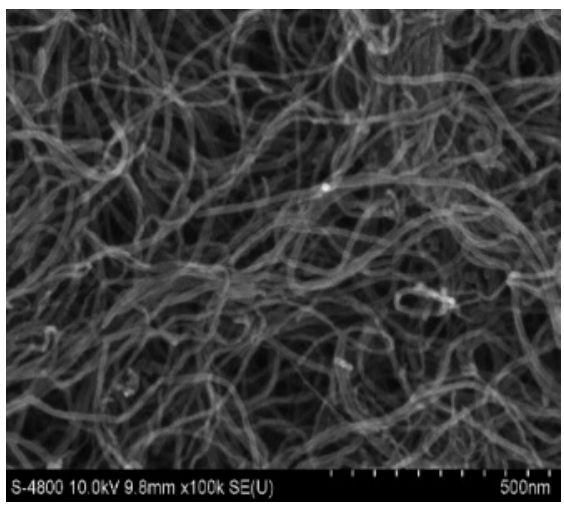

(d)

Fig. 4. The FE SEM images of Bukypaper samples fabricated by vacuum filtration technique with varied sonication power (a) $500 \mathrm{~W}$; (b) $700 \mathrm{~W}$; (c) $900 \mathrm{~W}$; and (d) $1000 \mathrm{~W}$.
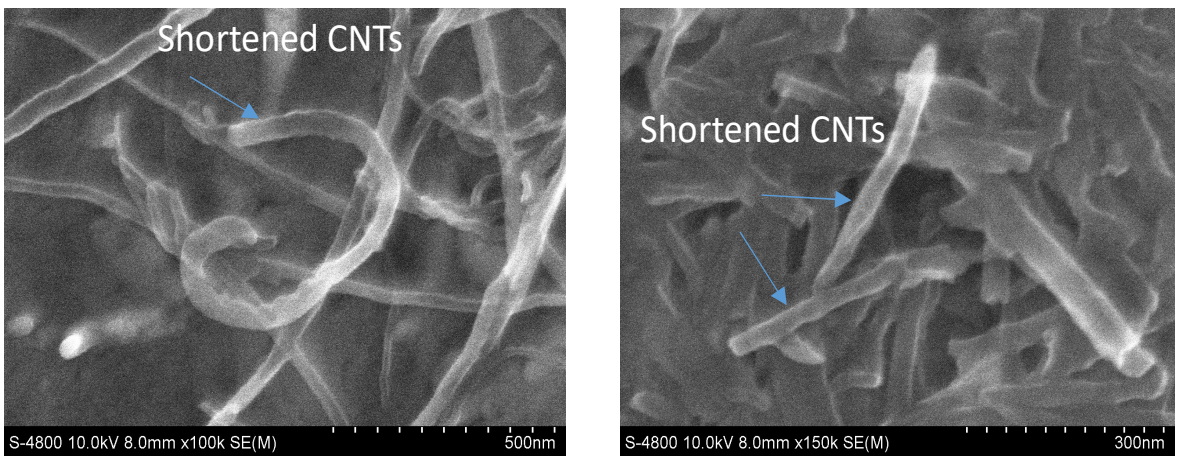

Fig. 5. The FE SEM images of shortened CNTs with the sonication time 45 minutes. 

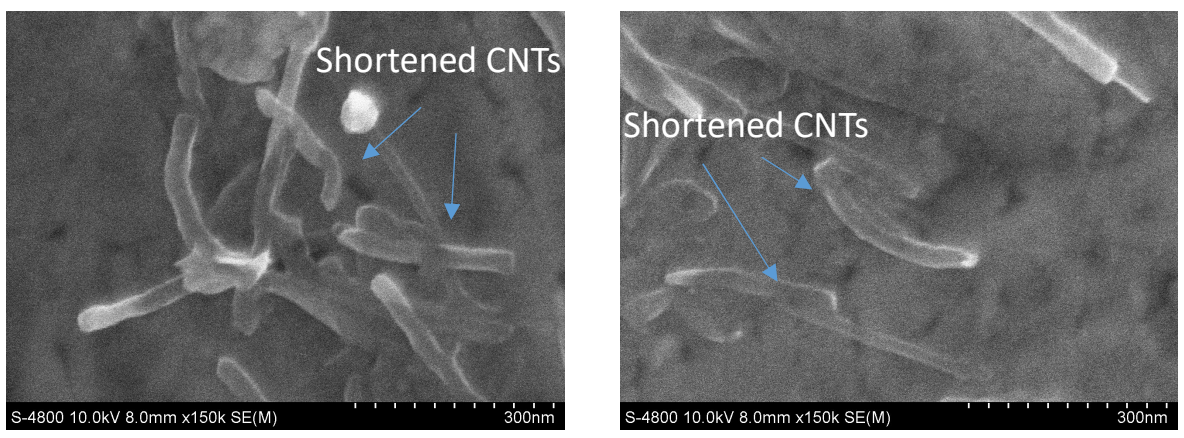

Fig. 6. The FE SEM images of shortened CNTs with the sonication time 60 minutes.

\section{III.2. Effect of sonication time and power on the properties of Buckypaper}

The Buckypaper's properties such as the thickness, electrical conductivity and surface area are important for battery and supercapacitor electrodes. We investigated the different sonication time and power affecting them.

We also see that solution of carbon nanotubes is more dispersion with the higher time and power sonication. This led the greater de-aggregation of carbon nanotubes and we can get smoother surface in Fig. 3 as well as the buckypaper thickness shown in Fig. 7. The sonication time 30 minutes is best dispersion ability and agreed with the [14].

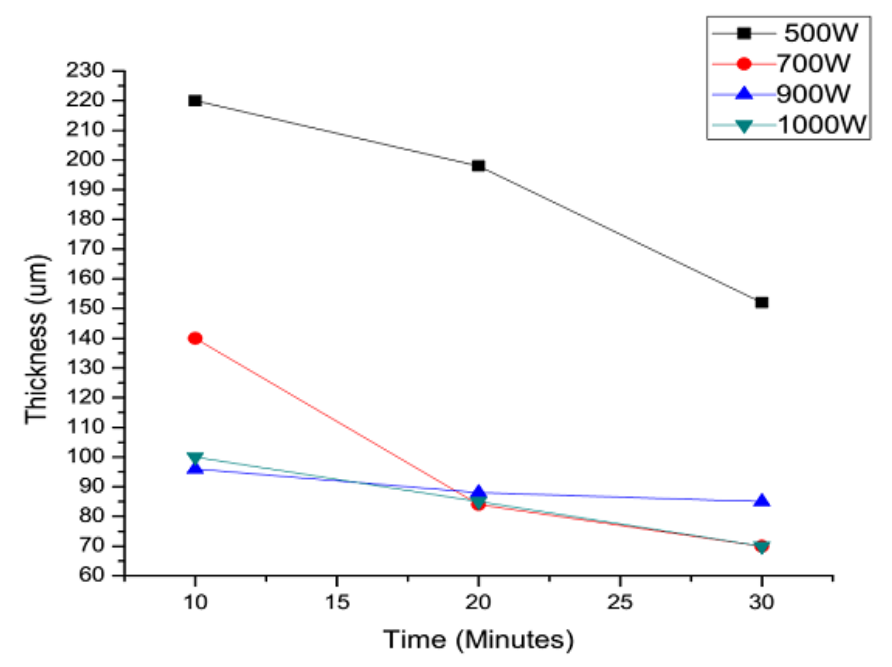

Fig. 7. The plot showed the effect of the sonication time and power on the Buckypaper thickness.

Besides, the sonication time and power effect on the electrical property of Buckypaper. The conductivity of Buckypaper is better with the higher time and power sonication. This explained that the carbon nanotube solution is more dispersion ability and leads the good de-aggregation and uniform distribution. This confirms again that the time sonication 30 minutes was for best 
solution dispersion and gave the saturation electrical conductivity $3.9 \times 10^{3} \mathrm{~S} / \mathrm{m}$ for 700,900 and $1000 \mathrm{~W}$ power sonication for both small and large scale Buckypaper shown in Fig. 8. The Table 1 summarizes the fabrication conditions and results for Buckypaper.

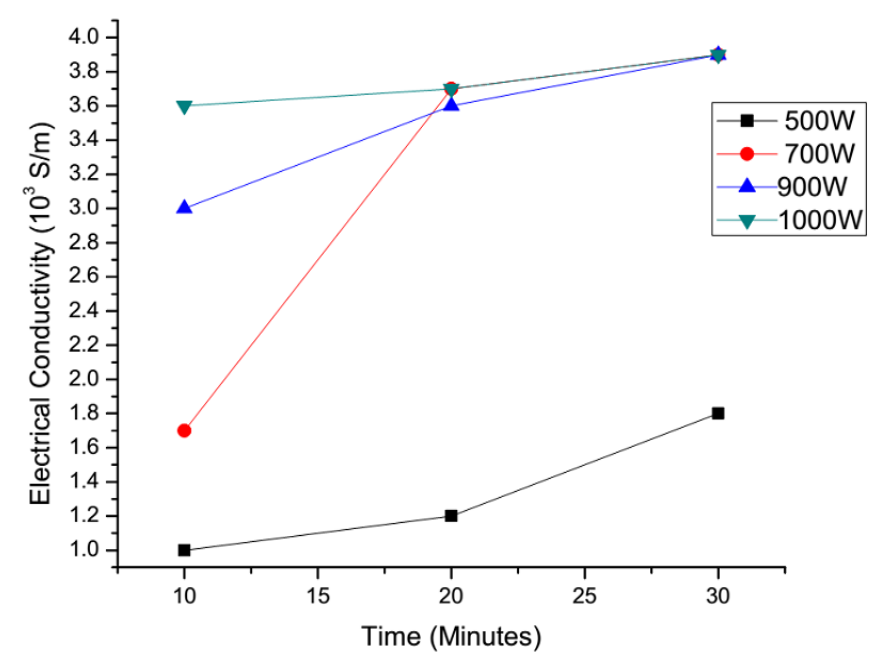

Fig. 8. The plot showed the effect of the sonication time and power on the Buckypapers electrical conductivity.

Table 1. The FE SEM images of the raw CNTs purchasing from manufacturer.

\begin{tabular}{|c|c|c|c|c|}
\hline Sample & $\begin{array}{c}\text { Sonication } \\
\text { Power } \\
\text { S }(W) \\
\end{array}$ & $\begin{array}{c}\text { Sonication } \\
\text { Time } \\
\text { (minutes) }\end{array}$ & $\begin{array}{l}\text { Thickness } \\
\quad(\mu \mathbf{m})\end{array}$ & $\begin{array}{c}\text { Electrical } \\
\text { Conductivity } \\
\left(\mathbf{1 0}^{3} \mathrm{~S} / \mathrm{m}\right)\end{array}$ \\
\hline 1 & 500 & \multirow{4}{*}{10} & 220 & 1 \\
\hline 2 & 700 & & 140 & 1.7 \\
\hline 3 & 900 & & 96 & 3.0 \\
\hline 4 & 1000 & & 100 & 3.6 \\
\hline 5 & 500 & \multirow{4}{*}{20} & 198 & 1.2 \\
\hline 6 & 700 & & 84 & 3.7 \\
\hline 7 & 900 & & 88 & 3.6 \\
\hline 8 & 1000 & & 85 & 3.7 \\
\hline 9 & 500 & \multirow{4}{*}{30} & 152 & 1.8 \\
\hline 10 & 700 & & 85 & 3.9 \\
\hline 11 & 900 & & 85 & 3.9 \\
\hline 12 & 1000 & & 70 & 3.9 \\
\hline
\end{tabular}

As buckypaper is used for electrode for supercapacitor so the surface are is important factor, showing the ability to store energy. Three samples no. 10, 11 and 12 in Table 1 showing the highest conductivity are brought to characterize. The surface area results are 200, 208 and 
$210 \mathrm{~m}^{2} / \mathrm{g}$, respectively. Again this explains that the higher sonication time and power make the carbon nanotube solution more dispersion ability and leads the good de-aggregation so the surface area is higher.

\section{CONCLUSION}

In summary, the MWNT Buckypaper was successfully fabricated by membrane filtration technique and evaluated. The sonication time is less than or equal 30 mintues and sonication power is $1000 \mathrm{~W}$ do not affect the carbon nanotubes quality. The sonication time 30 minutes gives the best solution dispersion, electrical conductivity and surface area as well. Additionally, the sonication power also affects those properties, higher power will result in higher conductivity. With these properties, Buckypapers can be applied for many potential applications including thermal pads, battery and supercapacitor electrodes...

\section{ACKNOWLEDMENTS}

Thanks the financial support from Ministry of Science and Technology Viet Nam for proposal "Study to fabricate the thin film thermal pad based on buckypaper for applications in the electrical and electronic devices" with code number ĐM.17.NC/16 and the contract No.01/2016/HĐCTĐMCN.

\section{REFERENCES}

[1] E. T. Thostenson, Z. Ren and T.-W. Chou, Composites Science Technology 61 (2001) 899.

[2] L. Dai, A. W. H. Mau, Advanced Material 13 (2001) 899.

[3] D. Wang, P. C. Song, C. H. Liu, W. Wu and S. S. Fan, Nanotechnology 19 (2008) 075609.

[4] Philip D. Bradford, Xin Wang, Haibo Zhao, Jon-Paul Maria, Quanxi Jia, Y. T. Zhu, Composites Science and Technology 70 (2010) 1980.

[5] J. Zhang, C. Jiang, D. Jiang, H. X. Peng, Phys. Chem. Chem. Phys. 16 (2014) 4378.

[6] Z. Wu, Z. Chen, X. Du, J. M. Logan, J. Sippel, M. Nikolou, K. Karamas, J. R. Reynold, D. B. Tanner and A. F. Hebard, Science 305 (2004) 1273.

[7] N. A. Kumar, I. Y. Joen, G. J. Sohn, R. Jain, S. Kumar, J. B. Beak, ACS Nano 5 (2011) 2324.

[8] R. Duggal, F. Hussain, M. Pasquali, Adv. Matter. 18 (2006) 29.

[9] R. C. Tenent, T. M. Barnes, J. D. Bergersion, A. J. Fergusion, B. To, L. M. Gedvilas, M. J. Heben, J. L. Blackburn, Adv. Matter. 21 (2009) 3210.

[10] N. Murata, J. Haruyama, J. Reppert, A. Rao, T. Koretsune, S. Saito, M. Matsudaira and Y. Yagi, Phys. Rev. Lett. 101 (2008) 27002.

[11] P. V. Kamat, K. G. Thomas, S. Barazzouk, G. Girishkumar, K. Vinodgopal, D. Meisel, J. Am. Chem. Soc. 126 (2004) 10757.

[12] R. Krupke, S. Linden, M. Rapp and F. Henrich, Adv. Matter. 18 (2006) 1468.

[13] Q. H. Do, C. Zeng, C. Zhang, B. Wang, and J. Zheng, Nanotechnology 22 (2011) 365402.

[14] L. J. Sweetman, L. Nghiem, I. Chironi, G. Triani, M. in het Panhuis and S. F. Ralph, J. Mater. Chem. 22 (2012) 13800. 